\title{
PERSPECTIVA DE ALUNOS DO ENSINO SUPERIOR SOBRE BRINQUEDOTECAS EM AMBIENTES VIRTUAIS DE APRENDIZAGEM
}

\author{
Luciane Guimarães Batistella Bianchini ${ }^{1}$ \\ Ana Lúcia Keiko Nishida² \\ Damares Luiza Silveira de Carvalho ${ }^{3}$
}

\begin{abstract}
RESUMO
Ambientes virtuais de aprendizagem tornaram-se espaços explorados pela geração atual. Neste contexto, as brinquedotecas virtuais configuram-se como locus atrativo por sua proposta de articulação entre ludicidade e tecnologia, sendo exploradas tanto por crianças como por adultos em cursos de formação. Os cursos de Pedagogia e de Design são os que mais utilizam estes espaços, mas será que alunos de diferentes áreas do conhecimento já tiveram acesso e experiência com brinquedotecas virtuais? O presente artigo analisou o acesso e a experiência com brinquedotecas virtuais por alunos de diferentes cursos do Ensino Superior e ainda registrou suas percepções sobre a inclusão desta ferramenta em seus processos formativos. A pesquisa caracterizada como qualitativa teve 1.441 alunos participantes, que responderam a um questionário on-line. Os resultados indicaram que a maioria dos alunos não teve acesso a brinquedotecas virtuais e aqueles que as experienciaram apresentaram percepções positivas, incluindo sentidos como inclusão social digital, interações entre real e virtual, busca pelo conhecimento de forma lúdica, etc. Concluiu-se que, na perspectiva dos alunos, as brinquedotecas em ambientes virtuais de aprendizagem, pelo potencial de conhecimento em rede que proporcionam, devem ser apresentadas por diferentes cursos como uma proposta inovadora de ensino e aprendizagem.
\end{abstract}

Palavras-chave: Brinquedoteca virtual. Ambientes de aprendizagem. Ensino Superior.

\section{PERSPECTIVE OF HIGHER EDUCATION STUDENTS ON PLAY ROOMS WITHIN VIRTUAL LEARNING ENVIRONMENTS}

\section{ABSTRACT}

Learning virtual environments became classrooms shared by the current generation. Within that context, virtual play rooms become an attractive locus due to its articulation proposal linking recreation with technology, being explored both by children as well as adults in undergraduate courses. Undergraduate courses on Pedagogy and Design are the ones which most make use of such classrooms, but have students of different fields of knowledge ever had access to them and experience within virtual play rooms? This paper analyzed both access and experience within virtual play rooms by students of different Higher Education courses and recorded their perceptions on the inclusion of that tool in their learning processes. Being a qualitative research, it comprised 1.441 participating students who responded to an online questionnaire. The results showed that most of the students had not had any access to virtual play rooms and those who had some previous experience in it found that such an experience was positive, including sharing feelings such as social digital inclusion, sharing real and virtual interactions, trying to achieve learning playfully, etc. One came to the conclusion that, from the students' perspective, play rooms within virtual learning environments, due to the network learning potential provided by them, must be presented within different courses as an innovating teaching and learning proposal for both college.

Keywords: Virtual play room. Learning environments. Higher Education.

Recebido em: $17 / 7 / 2020$

Aceito em: $3 / 8 / 2020$

\footnotetext{
Universidade Norte do Paraná - Unopar. Londrina/PR, Brasil. http://lattes.cnpq.br/5845155455423598. https://orcid.org/0000-00033523-2752.

2 Autora correspondente. Universidade Norte do Paraná - Unopar. Av. Paris, 675 - Jardim Piza. CEP 86041-100. Londrina/PR, Brasil. http:// lattes.cnpq.br/1164664984434806. https://orcid.org/0000-0001-8178-3438. ananishida@live.com

3 Universidade Norte do Paraná - Unopar. Londrina/PR, Brasil. http://lattes.cnpq.br/8254116673483523. https://orcid.org/0000-00034595-0758.
} 
Os ambientes virtuais de aprendizagem são cada vez mais utilizados como ferramenta para interagir e mediar o processo de construção do conhecimento do aluno (KENSKI, 2007; PAIVA, 2010; TONELLI; SOUZA, ALMEIDA; 2015; OLIVEIRA; CUNHA; NAKAYAMA, 2016; ZANI et al., 2019).

De acordo com Kenski (2007, p. 39), os ambientes virtuais de aprendizagem estão interligados em redes e formam "comunidades virtuais" de "pessoas ou instituições com características semelhantes e que funcionam dentro dos mesmos fluxos de processos produtivos". Isto se deve ao fato de que, na atualidade, tem-se uma geração caracterizada por experiências virtuais, incluindo aqui os novos hábitos com experiências lúdicas digitais (PRENSKY, 2012; EVANGELISTA, 2018).

A ludicidade faz parte da História da humanidade como manifestação cultural que se modifica continuamente, como pondera Huizinga (2008), ao destacar que o jogo é expressão histórico-cultural do homem.

Neste contexto de mudanças da atividade lúdica, verifica-se uma variação de objetos utilizados para o jogo e a brincadeira, com uma velocidade maior se comparada a outras gerações. O filósofo Bauman (2007) reflete sobre o tempo e as atividades do homem contemporâneo e ressalta que hábitos e rotinas mudam rapidamente. No caso da ludicidade, além da variação de objetos culturais, existem diferenças dos objetos lúdicos também nas diferentes regiões de um país (BIANCHINI; ARRUDA; GOMES, 2015).

A questão é que as mudanças na atividade lúdica da humanidade revelam as suas interações no mundo, ao mesmo tempo que indicam que, na atualidade, há predomínio no uso de objetos que envolvem tecnologias digitais (ROSADO, 2006; SILVA; BORTOLOZZI; MILANI, 2019). Muitos autores denominam de geração tecnológica ou nativos digitais $^{4}$ a geração atual pelo modo preponderante de interações que realizam mediadas pelas tecnologias em ambientes virtuais (PRENSKY, 2012).

A brinquedoteca virtual, por exemplo, é um destes ambientes recentemente explorados e que integra, num mesmo contexto, conhecimento, atividades lúdicas tanto para os alunos em cursos de formação quanto para crianças explorarem as suas brincadeiras livremente. Estes ambientes lúdicos dispõem de várias atividades, tais como: histórias, poemas, jogos, entre outras, e elementos como casas, plantas, máquinas, rios e qualquer objeto do mundo real (CUNHA, 1998; BIANCHINI; NISHIDA; CARVALHO, 2019).

Para Lira (2010), nesses ambientes de brinquedotecas virtuais o usuário pode interagir com cenários que simulam, ao máximo, a sensação de realidade. Há ambientes virtuais que tentam imitar os sentidos humanos, dando a sensação de realidade num ambiente que não existe fisicamente, permitindo, assim, que o usuário se sinta imerso.

Deste modo, pode-se perceber que a interação entre brincadeiras e brinquedos que promovem a ludicidade pode ser adaptada ao ambiente da tecnologia digital por meio de uma brinquedoteca. Neste contexto, proporcionam-se também novos modelos

Prensky (2001) criou a expressão "nativos digitais" para caracterizar crianças e adolescentes que nasceram a partir da década de 80 e que se desenvolveram utilizando em seu cotidiano objetos tecnológicos da cultura contemporânea. 
de interações, que embora não sejam realizadas "face a face" pelos participantes, auxiliam o processo de aprendizagem no atual cenário de intervenção por meio do uso de tecnologias digitais e acesso à informação.

Os Parâmetros Curriculares Nacionais - PCN - (BRASIL, 1997) já incentivavam o uso de tecnologias e ludicidade como recursos a serem incluídos em processos de aprendizagem, a fim de promover a inovação curricular e a qualidade do ensino. Na Base Nacional Comum Curricular - BNCC - (BRASIL, 2017), há orientações para a Educação Infantil e Ensino Fundamental, entre os quais a tecnologia é considerada como proposta de inclusão social. No referido documento enfatiza-se a importância de construir espaços com uso de tecnologias digitais de informação e comunicação de forma "crítica, significativa, reflexiva e ética nas diversas práticas sociais (incluindo as escolares) para se comunicar, acessar e disseminar informações, produzir conhecimentos" (BRASIL, 2017, p. 5).

Em recente pesquisa Ferreira (2020) analisou 310 alunos do curso de Pedagogia sobre sua experiência em brinquedotecas virtuais e concluiu que muitos exploram estes espaços, mas não analisam o contexto com um olhar pedagógico e crítico, que envolva pensar na efetividade de aprendizagem deste contexto. No curso em Educação a Distância (EaD) do qual estes alunos participavam, muitos sequer haviam entrado em contato com a brinquedoteca virtual disponibilizada pela instituição de ensino.

Alunos de outras áreas do conhecimento também experienciam as brinquedotecas em ambientes virtuais de aprendizagem, como é o caso da Graduação em Design. Neste curso, o desenvolvimento de projetos relacionados a brinquedos e ambientes de interação ocorre em virtude das demandas de aquisição e criação de locais destinados às atividades lúdicas (SOUSA, 2018).

Gonçalves (2009), Carvalho (2016) e Cavalcante Neto (2018) desenvolveram estudos sobre a exploração de brinquedotecas em ambientes virtuais de aprendizagem como recurso e ferramenta para o ensino em diferentes cursos.

O estudo de Gonçalves (2009), por exemplo, apresentou resultados do desenvolvimento de uma brinquedoteca virtual aplicada a turmas de 1. a 9.. ano do Ensino Fundamental. A aplicação foi positiva e validou a brinquedoteca virtual como uma ferramenta educacional no curso de Pedagogia.

Carvalho (2016) sugeriu um espaço virtual de brinquedoteca de modo colaborativo, também conhecido por Codesign. ${ }^{5} \mathrm{~A}$ proposta apresentada caracterizava-se como inovação nas concepções de projetos com a finalidade de utilizar a tecnologia como ferramenta para desenvolver ideias e definir decisões, favorecendo o uso de tecnologias no processo de ensino e aprendizagem de modo eficiente, claro e humanizado. Participaram deste projeto educacional profissionais de diferentes áreas: pedagogos, educadores, pesquisadores da Educação, além de profissionais das áreas de Tecnologia da Informação, Design e Contabilidade, envolvendo níveis técnicos, especialistas, mestres e doutores.

"[...], o termo Codesign tem sido utilizado pela comunidade de designers como abreviação para community design, collaborative design, cooperative design" (BARANAUSKAS; MARTINS; VALENTE, 2013, p. 25), significando um conjunto de ferramentas utilizadas por designers para engajar não designers no processo de design perguntando, ouvindo, aprendendo, comunicando e criando soluções colaborativamente. 
O estudo de Cavalcante Neto (2018) propôs a seis docentes do curso de Pedagogia a experiência de utilizar um protótipo de brinquedoteca virtual como "recurso tecnopedagógico" denominado por ele de Brincolife. Neste projeto o autor propõe aos docentes participantes da pesquisa que após conhecerem a brinquedoteca virtual e explorarem-na deveriam construir um plano de ensino com conteúdos a serem utilizados com seus alunos nesse ambiente virtual. Ao final, aplicou um questionário aos docentes para conhecer as suas percepções sobre a proposta. Concluiu que "virtualizar espaços é uma alternativa que amplia as possibilidades de toda a comunidade acadêmica, como também a sociedade que, por meio de dispositivos, acessam, pesquisam, conhecem e divulgam esses ambientes" e, assim, ajuda a sistematizar comunidades científicas em redes, promovendo conectividade entre quem ensina e quem aprende (CAVALCANTE NETO, 2018, p. 87).

Outro aspecto indicado por Cavalcante Neto $(2018$, p. 17) diz respeito à necessidade contemporânea de "socialização do conhecimento, tendo em vista a busca de resultados mediante a concepção de que a brinquedoteca virtual como ferramenta inovadora, tecnopedagógica, capaz de facilitar o entendimento de teorias de ensino-aprendizagem". E, "de forma prática, interativa e contextualizada, instiga novos olhares, debates e reflexões sobre o uso desta ferramenta nas diversas interfaces do conhecimento", bem como em diferentes cursos (CAVALCANTE NETO, 2018, p. 17).

Nesta perspectiva de ideias apresentadas até aqui, cabe questionar: Alunos de diferentes áreas do conhecimento têm acesso e experiência com brinquedotecas em ambientes virtuais?

O objetivo do presente artigo foi analisar o acesso e experiência de alunos de diferentes cursos do Ensino Superior em brinquedotecas virtuais, bem como registrou suas percepções sobre a inclusão desta ferramenta em seus processos formativos.

\section{MATERIAIS E MÉTODO}

A fim de responder aos objetivos do presente estudo, desenvolveu-se uma pesquisa qualitativa, que integra um projeto maior denominado "Jogos e tecnologias no processo de ensino e aprendizagem", aprovado pelo Comitê de Ética em Pesquisa da Universidade Pitágoras Unopar.

O método qualitativo é descrito por Minayo (2010) como recurso aplicado ao estudo das interpretações que os humanos realizam sobre um fenômeno. A apropriação dos detalhes destas interpretações possibilita melhor compreensão do pesquisador sobre a perspectiva do participante. No caso deste estudo, objetiva-se conhecer as percepções dos alunos sobre a brinquedoteca virtual em diferentes cursos formativos.

Os participantes foram alunos de diferentes cursos do Ensino Superior de uma Universidade particular da região norte do Paraná, com ofertas nas modalidades presencial, semipresencial e EaD.

Aos alunos foi realizado convite para participarem da pesquisa por meio de e-mail, totalizando 1.441 estudantes, que responderam com aceite ao Termo de Consentimento Livre e Esclarecido (TCLE).

A pesquisa ocorreu nos meses de abril e maio de 2020 e a coleta se deu mediante questionário on-line por meio do google forms (ferramenta do Google que permite a criação de formulários on-line), disponibilizado no ambiente virtual de aprendizagem da instituição. 
O questionário foi estruturado com perguntas abertas, fechadas e com escalas do tipo likert. No total foram apresentadas 15 questões aos alunos, das quais 8 serão contempladas neste estudo, sendo 3 do perfil do participante (idade, curso e modalidade) e 5 com questionamentos sobre: o acesso a alguma brinquedoteca em ambiente virtual de aprendizagem; o local em que estava disponível a brinquedoteca virtual; como foi a experiência; o que pensam sobre a presença de brinquedotecas virtuais (apenas para o curso de Pedagogia); e, por fim, qual(is) o(s) curso(s) que deveria(m) conhecer e experienciar brinquedotecas virtuais.

Durante a apresentação dos dados da pesquisa, com o intuito de preservar o anonimato, todos os alunos serão referenciados pela sigla "APp" - indicando "Aluno Participante da pesquisa".

Os dados resultantes das respostas dos participantes foram analisados quanti e qualitativamente. Para melhor organização foram divididos em dois eixos: a) Acesso e experiência em brinquedotecas presentes em ambientes virtuais de aprendizagem e b) Percepções sobre brinquedotecas virtuais em variados cursos de formação/graduação.

\section{RESULTADOS E DISCUSSÕES}

A brinquedoteca em ambientes virtuais de aprendizagem tem sido considerada um espaço de construção de conhecimento de modo colaborativo e necessário, por se tratar de um recurso e ferramenta inovadora lúdica para o ensino de alunos da geração contemporânea.

Neste contexto, muitas áreas de conhecimento podem recorrer ao espaço da brinquedoteca virtual para realização de atividades com seus alunos e foi com este propósito que se buscou verificar o acesso e a experiência de alunos de diferentes cursos do Ensino Superior (Gráfico 1) sobre brinquedotecas em ambientes virtuais de aprendizagem, bem como conhecer suas percepções sobre a inclusão dessa ferramenta em diferentes cursos no Ensino Superior.

\section{Gráfico 1 - Cursos dos participantes}

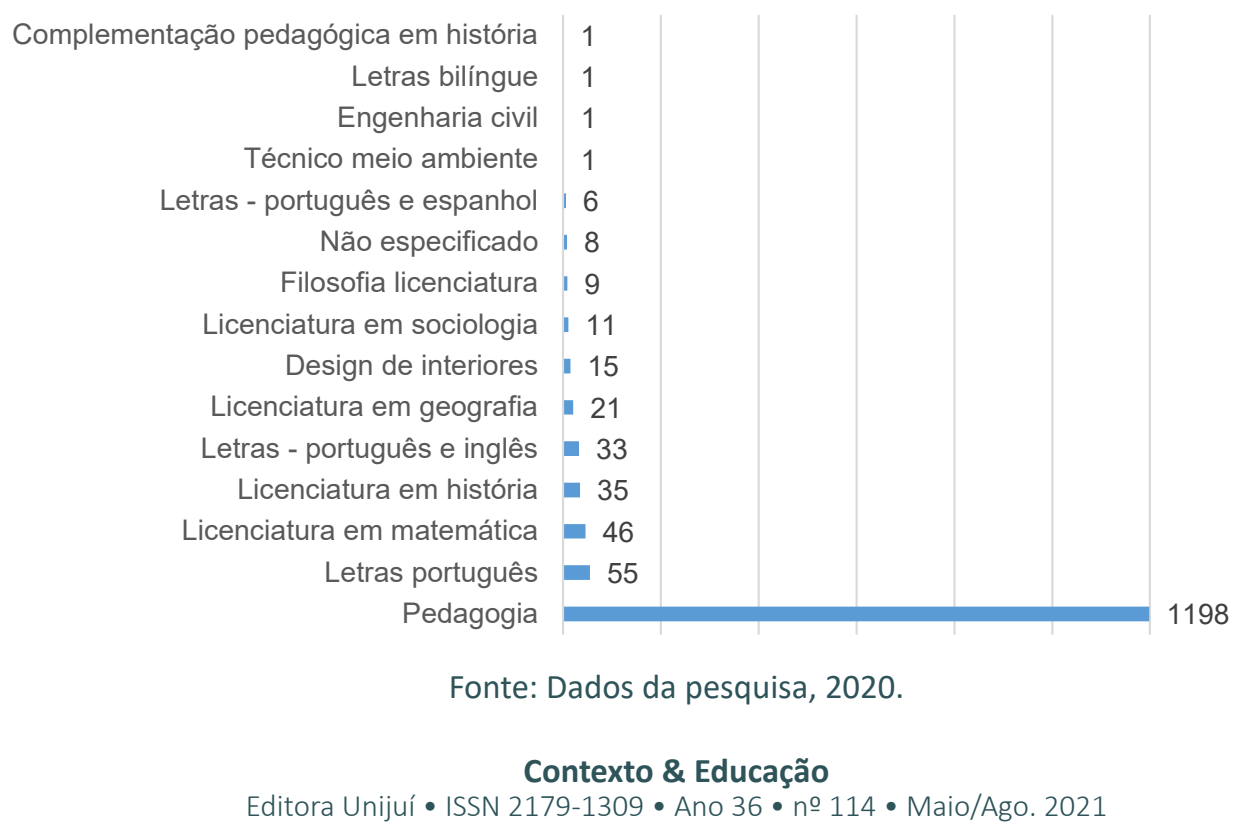


Observa-se que, embora o convite para participação na pesquisa tivesse sido estendido a vários cursos, o interesse em participar concentrou-se principalmente nos alunos de Pedagogia, com 1.198 respondentes.

Outra informação sobre o perfil dos participantes diz respeito à modalidade do curso que realizam. Como mostra o Gráfico 2, na modalidade semipresencial concentrou-se a maior parcela de alunos respondentes, seguido pela modalidade $100 \%$ a distância e, por último, a modalidade presencial.

Gráfico 2 - Modalidade de estudo

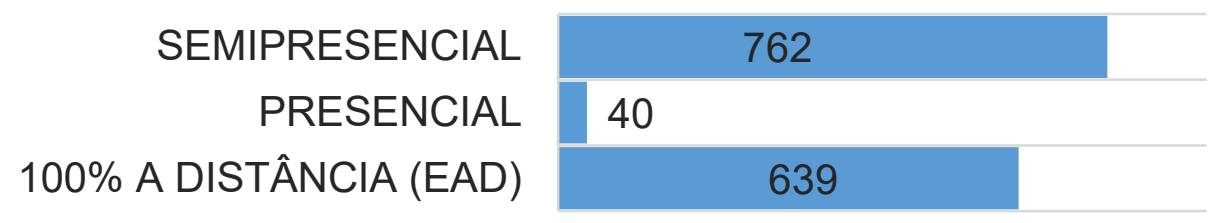

Fonte: Dados da pesquisa, 2020.

Sobre a faixa etária dos participantes, o Gráfico 3 informa que a maioria tem entre 18 e 50 anos de idade. Neste item do perfil pode-se perceber que a faixa etária se concentra entre 31 e 40 anos e de 18 a 25 anos; em seguida estão alunos de 41 a 50 anos e os de 26 a 30 anos. Também é possível perceber que existem alunos nas idades de 17 e de 51 a 62 anos de idade entre os respondentes, ou seja, a faixa etária dos alunos na comunidade estudantil da Graduação é diversa e bastante ampla.

\section{Gráfico 3 - Faixa etária}

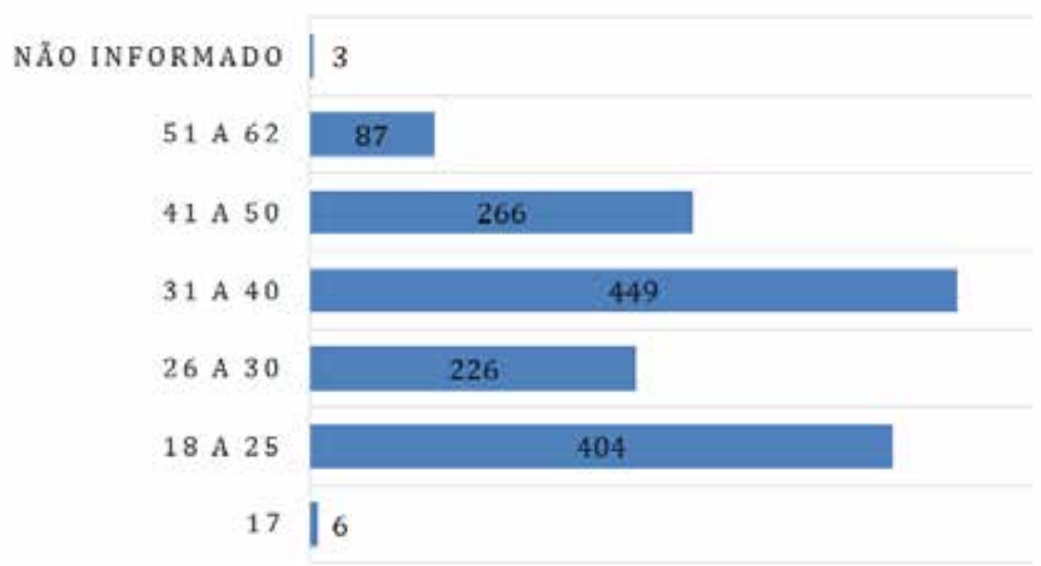

Fonte: Dados da pesquisa, 2020.

\section{ACESSO E EXPERIÊNCIA A BRINQUEDOTECAS EM AMBIENTES VIRTUAIS DE APRENDIZAGEM}

Iniciou-se perguntando aos participantes se eles já haviam acessado alguma brinquedoteca em ambiente virtual de aprendizagem. 


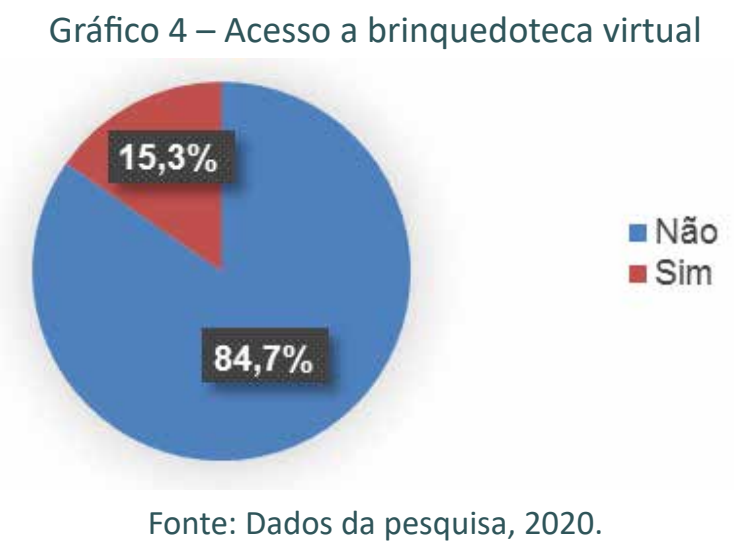

Os dados do Gráfico 4 permitem concluir que a maioria dos alunos não tinha acessado uma brinquedoteca virtual. Dos 15,3\% que responderam "sim", ou seja, 221 alunos, 194 eram do curso de Pedagogia, 8 do curso de Licenciatura em Matemática, 6 do curso de Letras - Português, 5 de Licenciatura em História, 4 do curso de Licenciatura em Geografia, 3 do curso de Letras - Português e Inglês, 1 do curso de Licenciatura em Filosofia e 1 do curso de Complementação Pedagógica em Sociologia.

Gráfico 5 - Prevalência dos cursos e alunos que conhecem a brinquedoteca virtual

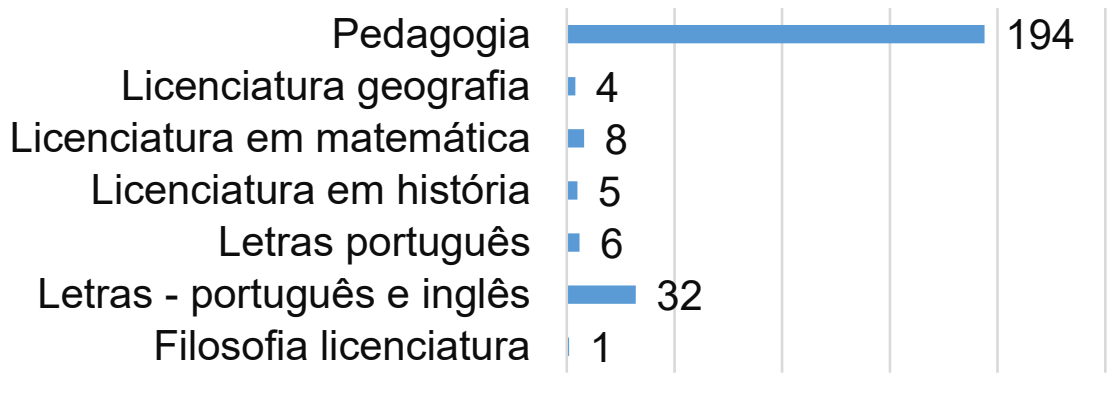

Fonte: Dados da pesquisa, 2020.

Outro ponto a destacar, como mostra o Gráfico 5, é a variedade dos cursos em que os alunos relataram conhecer uma brinquedoteca virtual, embora os resultados tenham indicado prevalência no curso de Pedagogia.

Vários autores que apresentaram propostas de brinquedotecas em ambientes virtuais as têm realizado preferencialmente nos cursos de Pedagogia. Carvalho (2016) foi um destes pesquisadores que propôs um espaço virtual como ferramenta para auxiliar alunos de "licenciatura, especialmente de pedagogia, em disciplinas que abordem temáticas da ludicidade, do jogo, da brincadeira e do desenvolvimento de determinados aspectos cognitivos, motores e afetivos" (p. 57).

A seguir, perguntou-se aos alunos sobre o local em que estava localizada a brinquedoteca virtual que haviam acessado. As respostas (Gráfico 6) a esse questionamento ficaram sobretudo entre o acesso aos ambientes virtuais de aprendizagem dos cursos que frequentam, com 111 respondentes, e blogs, com 76 respondentes. 
Gráfico 6 - Local onde acessaram a brinquedoteca virtual

\author{
Não especificado | 1 \\ No ambiente de trabalho 12 \\ Rede social $\| 2$ \\ Sites de interação \\ Aplicativos de jogos \\ Em um blog
}

No ambiente virtual do curso

Fonte: Dados da pesquisa, 2020.

Os alunos também expuseram sua opinião em relação à experiência de explorar a brinquedoteca virtual. Dos 221 participantes que disseram conhecer uma brinquedoteca virtual, a grande maioria relatou que a experiência foi positiva.

Por se tratar de uma resposta aberta e o número dos participantes ser grande, bem como a variedade de suas respostas, foram criadas quatro categorias. Como critério para agrupamento das respostas em categorias reuniu-se num mesmo grupo palavras que se repetiam ou eram semelhantes em seu significado. A seguir elegeu-se "títulos" que seriam representativos de cada categoria, a saber: Experiência de aprendizagem lúdica digital com o conhecimento; Experiência de Interação; Experiência de inclusão digital e Experiência entre real e virtual.

A categoria "Experiência de aprendizagem lúdica digital" permitiu observar, com base nas respostas dos alunos, que ao experienciar uma brinquedoteca virtual é possível "aprimorar o conhecimento de uma forma mais prazerosa e dinâmica"; "tornar o conhecimento mais atrativo", "sentir-se incentivado a ter ainda mais conhecimento de aprendizagem" (APp).

Pode-se inferir que a apropriação do conhecimento por meio das brinquedotecas virtuais são situações significativas na perspectiva do aluno. O aspecto afetivo relacionado ao conhecimento quando em situação lúdica fica evidente nestas respostas, que consideram o espaço atrativo, prazeroso e dinâmico. A resposta de um dos alunos expressa resumidamente a opinião dos demais quando diz: "É o lúdico interagindo com a tecnologia e conhecimento" (APp).

Para Gonçalves (2009), a brinquedoteca em ambientes virtuais de aprendizagem, mediados pelas tecnologias existentes, tem como característica algumas vantagens, uma vez que abre possibilidades diversas de aplicações para o processo de aprendizagem. Nas palavras do autor:

Vantagens de sua utilização nos processos ensino aprendizagem são propiciadas em função das características dessa tecnologia, que são: a reusabilidade (possibilidade de se utilizar um mesmo objeto de aprendizagem em diferentes aplicativos); adaptabilidade (capacidade de se adaptarem a diferentes ambientes de ensino); granularidade (possibilidade de se encapsular o conteúdo em partes); acessibili- 
dade (passível de ser acessado em diferentes plataformas); durabilidade (pode ser utilizada independente de alterações e atualizações tecnológicas) e interoperabilidade (atua em diferentes plataformas) (p. 49).

Outra categoria identificada e que merece reflexões foi sobre a "Experiência de Interação" promovida pelas brinquedotecas virtuais que os alunos conheceram.

De modo geral, a brinquedoteca foi considerada promotora da interação entre os participantes que, por pertencerem a uma geração tecnológica, têm também outras formas de interagir que são contempladas em ambientes virtuais. Nos contextos virtuais a interação, embora não ocorra face a face, apresenta características próprias e possíveis em ambientes virtuais. Neste aspecto vale destacar a fala de um dos participantes que considera a brinquedoteca virtual como "uma metodologia de ensino a favor da interação dos alunos nesta sociedade da informação" (APp).

Ainda sobre a interação na brinquedoteca virtual, um dos alunos respondeu que os espaços virtuais também podem atender a situações adversas nas quais as pessoas não podem estar presencialmente, como a situação atual de isolamento social (causada pela Covid-19) 6 vivenciada pela sociedade. "De acordo com a atual situação que enfrentamos, devido ao coronavírus, mostra-se uma ferramenta bastante eficaz tendo em vista que além de produzir atividades relacionadas aos conteúdos escolares, também proporciona às crianças uma interação ativa e colaborativa, assim evitando que as mesmas fiquem ociosas" (APp).

Carvalho (2016) identificou que propostas realizadas por meio de brinquedotecas virtuais tornam-se uma forma de envolver várias pessoas em uma situação de atividade e colaboração.

No trabalho de Bianchini, Oliveira e Vasconcelos (2012) também discutiu-se, entre outros assuntos, as interações em espaços virtuais. Os autores consideram que, no campo da virtualidade, as pessoas passam a interagir e fazer algo juntas. Mesmo que não convivam na mesma realidade, elas possuem objetivos comuns e isso possibilita a formação de novos grupos sociais.

Neste caso, as brinquedotecas virtuais podem ser um destes espaços de encontro de pessoas que se reúnem para jogar, brincar, etc. E é nesse sentido que a categoria "Experiência de inclusão digital" pode ser analisada como um espaço de interação, bem como de inclusão de pessoas.

A "Experiência de inclusão digital" permitiu aos respondentes perceber a importância de incluir nas atividades o uso da tecnologia como ferramenta de inclusão social de pessoas, como evidenciam as falas a seguir:

Covid-19 - é consequência de um novo coronavírus que pode evoluir provocando doenças graves e apresenta contaminação em potencial. Em 2020 o mundo foi acometido por uma pandemia decorrente deste vírus. 
Analisando o crescimento da informatização dos serviços oferecidos à sociedade atual, cada vez mais se busca a necessidade da inclusão digital dos cidadãos nesse modo de vida. Ao acontecer o uso destes recursos tecnológicos, eles devem ser apropriados de meios onde a tecnologia da informação e comunicação (TIC) se direcione para fazer valer a inclusão dos indivíduos neste ciberespaço (APp).

Anulando, assim, as diferenças sociais não pertinentes a este processo (APp).

Ampliar as oportunidades de acesso das crianças e o público em geral a jogos, brincadeiras e atividades lúdicas, culturais e estéticas (APp).

A inclusão digital é considerada relevante e necessária na perspectiva da BNCC. O documento indica que as mudanças sociais decorrentes da cultura digital tornaram-se significativas nas sociedades contemporâneas, em virtude do avanço e da multiplicação das tecnologias de informação e comunicação (uso de computadores, telefones celulares, tablets e afins).

Contudo, também é imprescindível que a escola compreenda e incorpore mais as novas linguagens e seus modos de funcionamento, desvendando possibilidades de comunicação (e também de manipulação), e que eduque para usos mais democráticos das tecnologias e para uma participação mais consciente na cultura digital. Ao aproveitar o potencial de comunicação do universo digital, a escola pode instituir novos modos de promover a aprendizagem, a interação e o compartilhamento de significados entre professores e estudantes (BRASIL, 2017, p. 61).

A experiência obtida com as brinquedotecas em ambientes virtuais possibilitou aos alunos ampliar o conhecimento e interagir com situações lúdicas reais num plano virtual. Interessante a seguinte fala de um dos alunos: "Assim, é possível a aproximação de todos os usuários de um modelo de brinquedoteca real" (APp).

Outra fala que merece destaque é quando um dos alunos participantes da pesquisa descreve sua experiência virtual dizendo: "A forma como pude ver uma brinquedoteca sem poder tocá-la foi de muito aprendizado" (APp).

A simulação do mundo real no ambiente virtual, segundo Evangelista (2018, p. 38), "possibilita em escalas maiores ou menores, que o indivíduo simule ambientes imaginários".

Lévy (2010, p. 17) denomina o espaço virtual como ciberespaço e assim o define:

O ciberespaço (que também chamarei de rede) é o novo meio de comunicação que surge da interconexão mundial dos computadores. O termo especifica não apenas a infraestrutura material da comunicação digital, mas também o universo oceânico de informações que ela abriga, assim como os seres humanos que navegam e se alimentam desse universo. Quanto ao neologismo cibercultura, especifica aqui o conjunto de técnicas (materiais e intelectuais), de práticas, de atitudes, de modos de pensamento e de valores que se desenvolvem juntamente com crescimento do ciberespaço.

Conclui-se, até aqui, que a virtualização de brinquedotecas em espaços ou ambientes virtuais de aprendizagem possibilita a comunidades, carentes de espaços de interação lúdica como a brinquedoteca física, que supram esta necessidade ao acessar um ambiente virtual e encontrem uma brinquedoteca rica em materiais, objetos e links que poderão levar a outros contextos para exploração do ciberespaço de maneiras inimagináveis. 


\section{PERCEPÇÕES DE ALUNOS EM RELAÇÃO À PRESENÇA DE AMBIENTES VIR- TUAIS COM BRINQUEDOTECAS EM CURSOS DE FORMAÇÃO/GRADUAÇÃO}

Com o objetivo de identificar as percepções dos alunos de diferentes cursos em relação à importância da brinquedoteca em cursos de formação, foi apresentada aos participantes a seguinte questão: As brinquedotecas virtuais devem ser destinadas apenas aos acadêmicos do curso de Pedagogia? O Gráfico 7 revela que 52\% dos respondentes discordaram.

\section{Gráfico 7 - Brinquedotecas virtuais destinadas apenas ao curso de Pedagogia}

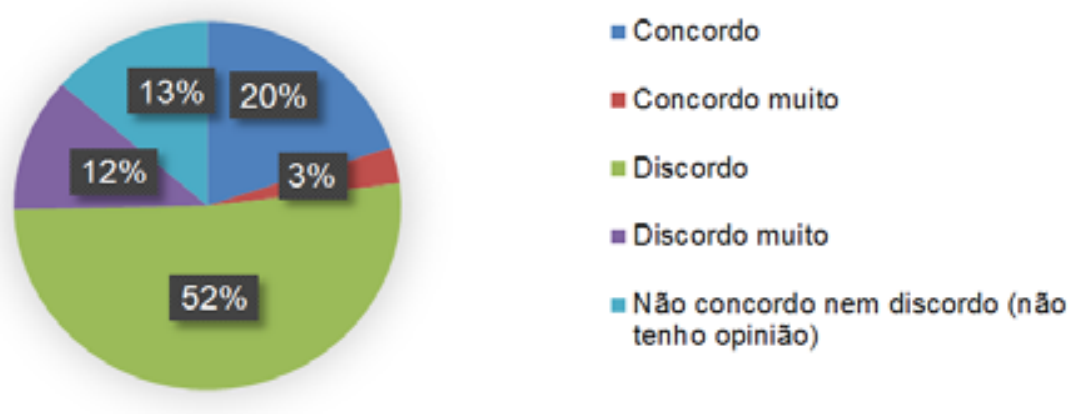

Fonte: Dados da pesquisa.

Quando questionados sobre qual(is) o(s) curso(s) deveria $(\mathrm{m})$ conhecer e experienciar o uso de brinquedotecas virtuais para incluir em processo de ensino e aprendizagem com os alunos as respostas obtidas para a questão (Gráfico 8) indicaram que todos os cursos devem conhecer e experienciar a brinquedoteca virtual. Entre as respostas encontram-se relatos que enfatizam a necessidade de incluir aspectos lúdicos na interação do indivíduo em relação à brinquedoteca virtual.

"O lúdico deve ser visto como algo favorável e imprescindível à necessidade do ser humano e facilita muito o professor conhecer, observar, saber de suas potencialidades, limitações e desenvolverá seu senso crítico, terá atitude de pesquisador sobre os seus alunos" (APp).

Gráfico 8 - Cursos que devem conhecer e experienciar a brinquedoteca virtual

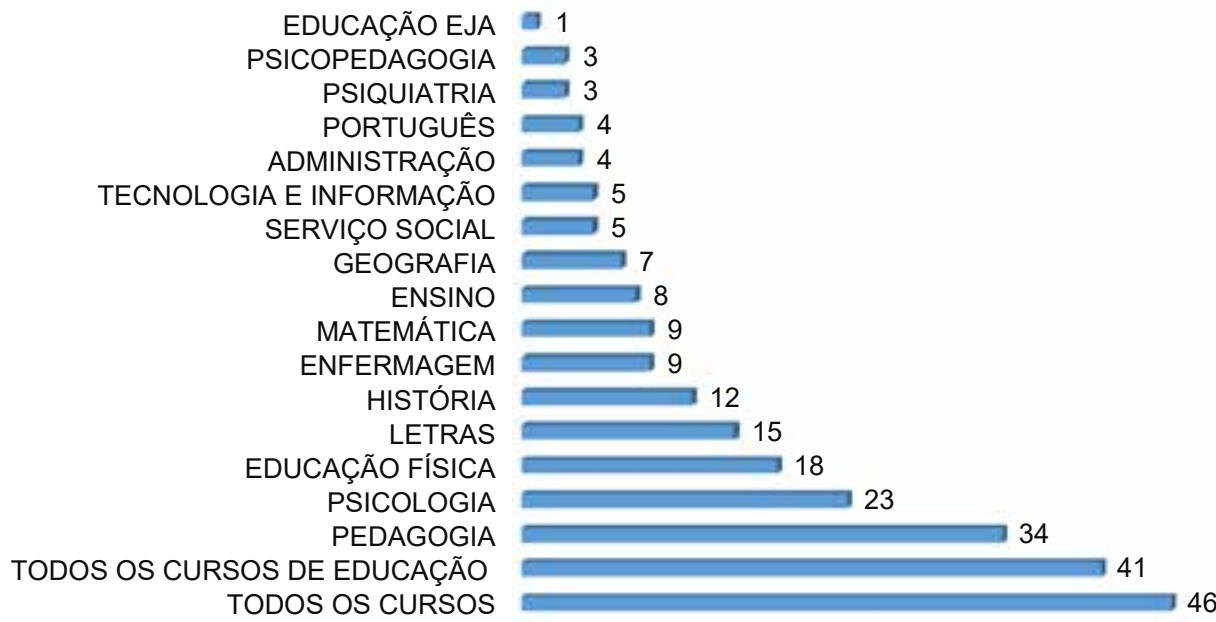

Fonte: Dados da pesquisa. 
Percebe-se que, do total de respostas recebidas durante o período de aplicação do questionário, poucos alunos tiveram a oportunidade de experienciar e experimentar uma brinquedoteca virtual, porém esta parcela teve uma interação positiva como usuário.

\section{CONSIDERAÇÕES FINAIS}

As brinquedotecas virtuais são ferramentas que contribuem para o ensino e aprendizagem das crianças bem como de profissionais de diferentes áreas em seus processos formativos. Sendo assim, o presente trabalho buscou descobrir se alunos de diferentes cursos do Ensino Superior tiveram experiência em brinquedotecas presentes em plataformas virtuais e como consideravam a inclusão desta ferramenta em seus processos formativos.

A maioria dos participantes não conhecia uma brinquedoteca virtual e os que conheciam relataram sua experiência de modo positivo em relação ao uso e à interação com o ambiente e suas ferramentas.

Os alunos ainda consideraram que os espaços virtuais de aprendizagem, como é o caso da brinquedoteca virtual, tornam-se experiência relevante para os futuros profissionais se encontrarem em redes colaborativas e, neste contexto, compartilharem conhecimentos de modo divertido e interessante. Por esta razão, não apenas os blogs, as redes sociais, os aplicativos de jogos devem investir nestas propostas, mas também, em especial, as plataformas dos cursos do Ensino Superior.

De modo geral foi possível concluir que a brinquedoteca virtual se caracteriza como espaço para novos hábitos lúdico-digitais da contemporaneidade. Neste ambiente os usuários têm a possibilidade de criar novos contextos, organizar e construir conteúdos compartilhados com outros usuários, bem como circular pelo ciberespaço, ao mesmo tempo que colocam em atividade a aprendizagem e exercitam a criação de maneiras inimagináveis, que somente espaços como estes, que envolvem ferramentas com tecnologias digitais, podem possibilitar.

\section{REFERÊNCIAS}

BARANAUSKAS, M. C.; MARTINS, M. C.; VALENTE. J. A. (org.). Codesign de redes digitais: tecnologia e educação a serviço da inclusão social. Porto Alegre: Penso, 2013.

BAUMAN, Z. Tempos líquidos. 2. ed. Rio de Janeiro: Zahar, 2007.

BIANCHINI, L. G. B; ARRUDA, R. B.; GOMES, L. R. Ludicidade e educação. Londrina: Educacional, 2015.

BIANCHINI, L. G. B; OLIVEIRA, F. N.; VASCONCELOS, M. S. Procedimentos no jogo virtual Colheita Feliz: entre a virtude e a regra. ETD: Educação Temática Digital, Campinas, v. 14, n. 1, p. 1-21, jan./jun. 2012.

BRASIL. Ministério da Educação. Base Nacional Comum Curricular. Brasília: MEC, 2017. Disponível em: http://basenacionalcomum.mec.gov.br/images/BNCC_El_EF_110518_versaofinal_site.pdf. Acesso em: 26 jun. 2020.

BRASIL. Secretaria de Educação Fundamental. Parâmetros Curriculares Nacionais: introdução aos parâmetros curriculares nacionais. Brasília, DF: MEC; SEF, 1997. Disponível em: http://portal.mec.gov.br/seb/ arquivos/pdf/livro01.pdf. Acesso em: 26 jun. 2020.

CARVALHO, F. R. de. O espaço do brincar: um estudo sobre o Codesign pedagógico para ambientes virtuais. 2016. 100 f. Dissertação (Mestrado em Educação) - Universidade Federal do Amazonas, Manaus, 2016.

CAVALCANTE NETO, F. S. BRINCOLIFE: uma ferramenta para ensino-aprendizagem no curso de Pedagogia. 2018. 103 f. Dissertação (Mestrado em Tecnologia e Gestão em Educação a Distância) - Universidade Federal Rural de Pernambuco, Recife, 2018. 
CUNHA, N. H. da S. Brinquedoteca: definição, histórico no Brasil e no mundo. In: FRIEDMANN, A. et al. $O$ direito do brincar: a brinquedoteca. São Paulo: Edições Sociais: Abrinq, 1998. p. 39-52.

EVANGELISTA, V. de M. A. Paraísos virtuais: um estudo sobre jogos eletrônicos e moralidade no mundo contemporâneo. 2018. 242 f. Tese (Doutorado em Psicologia) - Faculdade de Ciências e Letras, Universidade Estadual Paulista, Assis, 2018. Disponível em: https://repositorio.unesp.br/bitstream/handle/11449/157424/evangelista_vma_dr_assis_par_sub.pdf?sequence=9\&isAllowed=y. Acesso em: 26 jun. 2020.

FERREIRA, R. B. Perspectiva de alunos do curso de pedagogia EaD sobre brinquedotecas presentes em centros municipais de educação infantil brasileiros. 2020. 88 f. Dissertação (Mestrado em Metodologia do Ensino de Linguagens e suas Tecnologias) - Universidade Pitágoras Unopar, 2020.

GONÇALVES, M. M. Brinquedoteca virtual escolar: possível aproximação da criança ao brincar e à aprendizagem. 2009. 130 f. Dissertação (Mestrado em Engenharia e Gestão do Conhecimento) - Universidade Federal de Santa Catarina, Florianópolis, 2009.

HUIZINGA, J. Homo ludens. 5. ed. São Paulo: Perspectiva, 2008.

KENSKI, V. M. Educação e tecnologias. Campinas: Papirus, 2007.

LÉVY, P. Cibercultura. Tradução Carlos Irineu da Costa. 3. ed. São Paulo: Editora 34, 2010.

LIRA, R. P. de. Ambiente virtual de aprendizagem infantil. 2010. 188 f. Dissertação (Mestrado em Ciência da Computação) - Universidade Federal de Pernambuco, Recife 2010. Disponível em: https://repositorio. ufpe.br/handle/123456789/2358. Acesso em: 6 jun. 2020.

MINAYO, M. C. S. O desafio do conhecimento: pesquisa qualitativa em saúde. 12. ed. São Paulo: Hucitec; Abrasco, 2010.

NISHIDA, A. L. K.; BIANCHINI, L. G. B.; CARVALHO, D. L. Hipermídia e recursos visuais em brinquedotecas virtuais: novas formas para aprender e ensinar. In: ENCONTRO DE ATIVIDADES CIENTÍFICAS - EAC, 22., 2019, Londrina. Anais [...]. Londrina: Universidade Norte do Paraná, 2019. Disponível em: file://C:/Users/user/Downloads/trabalho.pdf. Acesso em: 4 jul. 2020.

OLIVEIRA, P. C. de; CUNHA, C. J. C. de A.; NAKAYAMA, M. K. Ambientes virtuais de aprendizagem e gestão da educação a distância: uma revisão integrativa e agenda de pesquisa. JISTEM, São Paulo, v. 13, n. 2, p. 157180, ago. 2016.

PAIVA, V. M. de O. Ambientes virtuais de aprendizagem: implicações epistemológicas. Educação em Revista, Belo Horizonte, v. 26, n. 3, p. 353-370, dez. 2010.

PRENSKY, M. Aprendizagem baseada em jogos digitais. São Paulo: Editora Senac, 2012.

PRENSKY, M. Digital natives, digital immigrants part 1. On the horizon, v. 9, n. 5, p. 1-6, 2001. Disponível em: https://doi.org/10.1108/10748120110424816. Acesso em: 26 jun. 2020.

ROSADO, J. dos R. História do jogo e o game na aprendizagem. In: SEMINÁRIO JOGOS ELETRONICOS, EDUCAÇÃO E COMUNICAÇÃO, 2., 2006, Salvador. Anais [...]. Salvador: Uneb, 2006. Disponível em: http://www. comunidadesvirtuais.pro.br/seminario2/trabalhos/janaina.pdf. Acesso em: 26 jun. 2020.

SILVA, E. R. T.; BORTOLOZZI, F.; MILANI, R. G. O brincar digital e o uso das tecnologias na saúde das crianças. Perspectivas em Diálogo, Naviraí, v. 6, n. 13, p. 125-138, 2019.

SOUSA, L. B. Design no brincar: uma compreensão da tríade indústria - Formação em Design - Brinquedo. 2018. 114 f. Dissertação (Mestrado em Design) - Pontifícia Universidade Católica do Rio de Janeiro, Rio de Janeiro, 2018.

SOUSA, R. P.; MOITA, F. M. C. da S. C.; CARVALHO, A. B. G. (org.). Tecnologias digitais na educação. Campina Grande: EDUEPB, 2011.

TONELLI, E.; SOUZA, C. H. M. de; ALMEIDA, F. M. de. A práxis docente nos ambientes virtuais de aprendizagem no contexto da dialogicidade. Observatório (OBS*), Lisboa, v. 9, n. 1, p. 149-158, jan. 2015.

ZANI, F. F. et al. Ambiente virtual de aprendizagem na formação continuada de docentes. Revista Brazilian Journal of Development, Curitiba, v. 5, p. 29.316-29.324, 2019. 